\title{
Economic Analysis of the Eradication and Management of Invasive Alien Vegetation in the Mhlatuze River Catchment (KwaZulu-Natal, South Africa)
}

Jennifer Cooper and Jessica Schroenn

School of Business, University of Natal, Pietermaritzburg

Nevil Quinn

Centre for Environment and Development, University of Natal, Pietermarizburg

\section{ABSTRACT}

Alien invasive vegetation threatens the functioning and existence of natural ecosystems in South Africa because many of these plants have no predators or competitors, allowing them to dominate the ecosystem which they inhabit. The rapid proliferation of this alien vegetation, ascribed to the increase in afforestation and changes in land use, has had significant adverse impacts on water resources, biodiversity and the stability as well as integrity of these ecosystems. Although eradicating alien invasive vegetation gives rise to a number of different benefits, this process entails enormous costs. Consequently, in order to establish the economic viability of alien plant eradication it is essential to analyse these costs as well as the benefits associated with eradication.

JEL Q20

\section{INTRODUCTION}

The Mhlatuze River Catchment, which is considered the most severely affected tertiary catchment in KwaZulu-Natal in terms of alien vegetation infestation, was selected as the focus of this study. Although the cost-benefit analysis (CBA) was conducted in a small area, its findings can be extended to regional, national or even global situations. At the very least, this analysis offers insight into the feasibility of alien plant eradication and ascertains whether or not this eradication is beneficial to both landowners and the broader society.

This paper reviews the literature pertaining to alien invasive vegetation and outlines the methods selected for valuing the impacts of its eradication. Based 
on the analysis of data generated by the study, the economic efficiency of the clearing process was established, and future actions required to manage invasive alien vegetation identified.

\section{THEORETICAL FRAMEWORK}

The prevalent attitude towards eradicating alien invasive vegetation among timber producers is one of apathy; most producers undertake sporadic clearing, rather than the rigorous removal and sustained management of alien plants. In order to uncover the economic rationale for these attitudes, it is helpful to consider the economic theory underlying project appraisals as well as sources of inefficiency which lead to market failure.

The Hicks-Kaldor criterion (i.e. accept any project which results in a potential Pareto improvement) is central to the theoretical justification of CBA in welfare economics and provides the rationale for selecting projects whose benefits outweigh their costs (Perkins, 1994: 50). CBA is purely concerned with the economic efficiency of a project and whether or not this increases social welfare. Equity effects are thus ignored: the project decision does not depend on to whom the benefits and costs accrue, or on whether society considers the prevailing distribution of income to be desirable. Some CBA frameworks, for example that proposed by the World Bank, address this issue by advocating the use of distributional weights.

In the idealised world of perfect competition, the interaction of many profitmaximising producers and utility-maximising consumers gives rise to a Paretooptimal situation, which is efficient. Under these circumstances, prices reflect marginal economic costs and the private and social optimums coincide (Munasinghe, 1993: 1732). The existence of prices means that scarcity can be gauged through the market forces of demand and supply, which ensures the efficient allocation of society's scarce resources (Perkins, 1994: 95).

In the real world, however, distortions ascribed to monopoly practices, extemal economies and diseconomies, or interventions in the market process culminate in market (or financial) prices for goods and services that do not fully reflect the marginal benefit of their consumption to society and which may diverge substantially from their true economic values or shadow prices (Munasinghe, 1993: 1732). The failure of the market to price resources efficiently inevitably leads to their over-exploitation and/or inefficient utilisation. Consequently, an argument can be developed for government intervention. 
An externality exists where the action of one economic agent affects the utility or production possibilities of another in way that is not reflected in the marketplace (Just et al., 1982: 269). Externalities are particularly relevant to this study, since those individuals not currently engaging in alien plant eradication produce more output than the socially optimal level and adversely affect the welfare of downstream users, who as a result of this inactivity produce less output than the social optimum.

In practice, the correction of such distortions is difficult, since many environmental effects (e.g. increased biodiversity) display public good aspects (i.e. non-rivalry and non-exclusiveness in consumption), and fail to be recorded by market price movements. This explains why environmental effects are often excluded from analyses. For purposes of this study, environmental goods and services are relevant both in carrying out the CBA of eradicating invasive alien plants as well as the resulting decision on project choice (Hanley \& Spash, 1993: 10). Thus, it is imperative to ensure that such effects are included and, where possible, quantified.

\section{IMPACTS ASSOCIATED WITH ALIEN INVASIVE VEGETATION}

The invasion of natural ecosystems by alien plants is a serious environmental problem that threatens the sustainable use of benefits derived from such ecosystems (Van Wilgen et al., forthcoming: 2). Although alien invasive vegetation may have benefits, for example it may provide food for human consumption (e.g. guavas) or may have aesthetic beauty, substantial costs are associated with this vegetation. Adverse impacts include:

- Streamflow reduction;

- Loss of biodiversity (as well as ecosystem resilience);

- Increased costs of fire protection and damage in wildfires;

- Loss of potentially productive land and

- Loss of grazing potential and livestock production (DWAF, 2000: 16).

\section{CHARACTERISTICS OF THE MHLATUZE CATCHMENT}

The study area comprises a total of 48633 hectares, of which approximately eight per cent ( 3767 hectares) is densely infested with invasive alien vegetation. This heavy infestation is ascribed to the establishment of plantations of alien species as well as changes in land use. The area is dominated by the agricultural, forestry and industrial sectors, all of which are important in terms 
of their contribution to the local economy and/or their employment of local people.

The Mhlatuze Catchment has been classified as 'water stressed', since more water has been allocated to users than is actually available (Versveld et al, 2000: v). It is anticipated that this scenario will deteriorate in the future, due to increased demand as a result of population and economic growth as well as the launching of the Richards Bay SDI. Furthermore, this catchment is characterised by high levels of unemployment, with most people in the rural areas engaged in a subsistence lifestyle.

\section{METHODOLOGY}

A multidisciplinary approach was adopted to document the findings of this study due to the wide range of biological, economic and social implications associated with the eradication of invasive alien vegetation. Data were gleaned from an array of sources, which included books, journals, reports and government as well as policy documents. The research area was visited on a number of occasions and formal in-depth interviews were conducted with experts, major stakeholders and WFW employees. The purpose of these interviews was to identify the most significant impacts and capture salient information concerning the actual costs and benefits associated with the eradication process. A total of thirteen stakeholders located in the study area and five experts were interviewed. In addition, thirty Working for Water (WFW) employees residing and working in the study area were interviewed in order to evaluate the social effects of alien plant eradication, and to establish the benefits received from the WFW Programme.

Based on the responses elicited and on the literature survey conducted, those impacts with the highest relative importance were identified. The impact parameters selected include: harvesting of alien vegetation, streamflow amount, biodiversity and fire control. Where possible, the values of impact parameters connected with the eradication process were quantified.

All the data generated from this process were used to compile the results section of the report, and based on the findings, suitable recommendations were formulated. 


\section{RESULTS AND DISCUSSION}

Analysis of the results indicates that all the private farmers and other major stakeholders in the study region are engaged in some form of alien plant control. However, this clearing has been more rigorous on private farmland.

\subsection{Costs associated with alien invasive plant eradication}

Alien plant eradication costs are dependent on the control method adopted (mechanical, chemical or biological control), as well as on the stage and frequency of clearing. Individuals in the study area use mechanical as well as chemical control methods, and are responsible for the full costs connected with alien plant eradication, except where the WFW Programme is operating on the individual's land.

The costs associated with these control methods include capital, operating and maintenance costs as well as the costs of follow-up operations. Rehabilitation costs are excluded from this analysis, since it was evident from stakeholder responses that no individual had been engaged in such a process.

The total costs of eradicating alien invasive vegetation depend on the degree of infestation (the density of alien plant cover), the type and age of the invasive species, and ease of access to the area (Hosking \& Du Preez, 1999: 445). The total costs associated with clearing alien plants over a ten-year period were elicited from stakeholders. It was estimated that on average 65 per cent of the total costs pertained to labour, whilst 25 and 10 per cent were correlated to herbicide and other costs like hired equipment and transport respectively. The average costs associated with the various phases of alien plant removal (refer to Table 1) are based on the above categorisation and on the following assumptions:

- The average weighted daily wage rate for labourers was fixed at R25 per person.

- All stakeholders adopted the same control methods.

- Garlon was the only herbicide considered in this analysis, since it was found that over 85 per cent of stakeholders in the area used Garlon. The cost of Garlon is R142 per litre (PPRI, 2000: 20).

- Four follow-up operations were required to ensure alien plant density declines to less than 10 per cent cover (Goodall pers comm.).

- Each stage of eradication is initiated annually in order of sequence (refer to Table 1). 
Table 1 Total costs associated with eradicating alien invasive vegetation for different phases

\begin{tabular}{|l|c|c|c|c|}
\hline $\begin{array}{c}\text { Stages of eradi- } \\
\text { cation }\end{array}$ & $\begin{array}{c}\text { Labour cost } \\
\text { (Rands/hectare) }\end{array}$ & $\begin{array}{c}\text { Herbicide cost } \\
\text { (Rands/ } \\
\text { hectare) }\end{array}$ & $\begin{array}{c}\text { Other costs } \\
\text { (Rands/ } \\
\text { hectare) }\end{array}$ & $\begin{array}{c}\text { Total cost } \\
\text { (Rands/ } \\
\text { hectare) }\end{array}$ \\
\hline Initial eradication & 1,300 & 500 & 200 & 2,000 \\
\hline First follow-up & 494 & 190 & 76 & 760 \\
\hline Second follow-up & 280 & 107 & 43 & 430 \\
\hline Third follow-up & 156 & 60 & 24 & 240 \\
\hline Fourth follow-up & 123 & 48 & 19 & 190 \\
\hline Maintenance & 104 & 40 & 16 & 160 \\
\hline
\end{tabular}

This table highlights that so long as regular (that is, at least annual) alien plant eradication is carried out, total costs associated with clearing will decline with each successive year up until the maintenance phase, where costs will stabilise. Using the total invaded area of 3767 ha in the study region and the costs referred to in the table above, it is instructive to depict the change in total costs associated with alien plant eradication over the ten-year lifespan of the project (refer to Figure 1). It must be noted that the total costs will only follow this given trend if each and every eradication phase is properly and effectively implemented.

Figure 1 Total costs associated with eradication in the study area

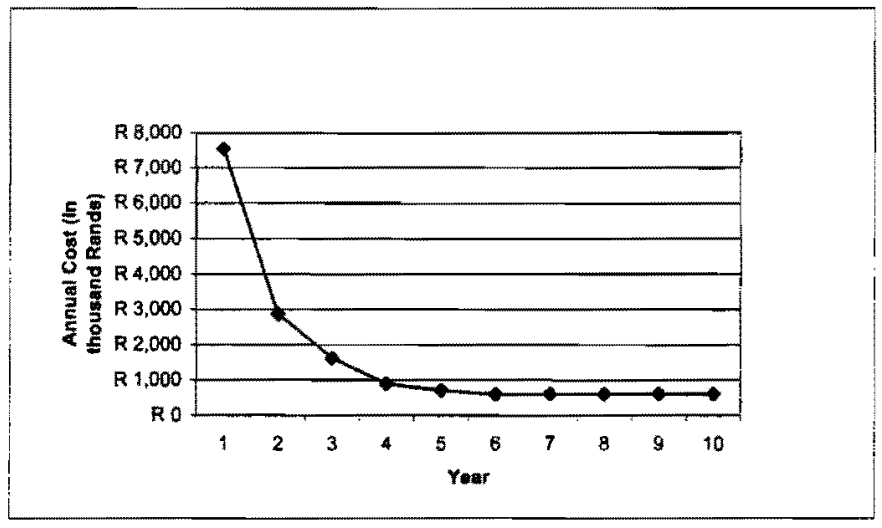




\subsection{Benefit flow of alien vegetation eradication}

It is necessary to distinguish between private and social benefits in this analysis, to establish the positive impacts of alien plant eradication and to highlight the distribution of these benefits. The ignorance of social benefits has given rise to the misallocation of resources in the past, and their inclusion in this analysis is thus a significant aspect of the study.

\subsubsection{Private benefits}

Private benefits are those accruing entirely to the proprietor, for example, income derived from the harvesting of alien vegetation and reduced fire management costs. Monetary values for such benefits are generally easy to derive from markets.

\section{a) Utilisation of alien vegetation}

The harvesting of alien vegetation is a consumptive use value that is dependent on the species eradicated, the relative age and the extent of infestation. From interviews conducted, it was apparent that the only alien invasive vegetation harvested were commercial timber species (Eucalyptus, Pinus and Acacia mixed species). Stakeholders estimated that on average, 20 tonnes of timber per densely invaded hectare were likely to be extracted in the initial phase of eradication. Further, they confirmed that there would be market demand for this additional timber at current prices. Thus to derive a monetary value for this vegetation, the extraction rate was multiplied by the profit per tonne (i.e. the market price less transport and processing costs) derived from the different timber species used for paper and pulp purposes, and summed (refer to Table 2).

Table 2 Total value (August 2001 values) of commercial forestry species located in invaded areas of study area

\begin{tabular}{|c|c|c|c|c|}
\hline $\begin{array}{l}\text { Commercial } \\
\text { forestry species }\end{array}$ & $\begin{array}{c}\text { Size of area } \\
\text { (hectares) }\end{array}$ & $\begin{array}{c}\text { Tonnes of timber } \\
\text { to be extracted } \\
\text { per hectare }\end{array}$ & $\begin{array}{l}\text { Average profit } \\
\text { per tonne } \\
\text { (Rands) }\end{array}$ & $\begin{array}{c}\text { Total value } \\
\text { (Rands) }\end{array}$ \\
\hline Eucalyptus spp. & 68 & 20 & $R 200$ & R 272,000 \\
\hline Pinus spp. & 26 & 20 & $\mathrm{R} 130$ & R 67,600 \\
\hline Acacia mixed spp. & 1921 & 20 & R290 & R $11,141,800$ \\
\hline TOTAL & 2015 & - & - & R $11,481,400$ \\
\hline
\end{tabular}

1 Area occupied by harvestable commercial forestry species within the densely invaded area of the study region (i.e. 3767 hectares).

2 This is with reference to the initial eradication phase only. 
3 Average profit (i.e. net of costs) for specified commercial timber, which was derived from stakeholders in the study area (August 2001).

The value of harvesting alien vegetation in the initial phase of eradication in the study region amounts to R11 481400 (refer to Table 2). The largest proportion of this potential income will accrue from the harvesting and sale of Acacia species, which occupy 51 per cent of the total invaded area. This is based on the assumption that the entire invaded area is cleared in the first year.

\section{b) Costs associated with burning}

From questionnaires administered, it was estimated that the average cost of burning open grassland per hectare is R46/ha per annum. The presence of alien invasive vegetation increases this average cost to $R 74 /$ ha per annum. Consequently, ceteris paribus, alien plant eradication would reduce fire hazard or management costs by the same proportion, that is R28/ha per annum or 60 per cent. In order to establish the annual reductions in fire management costs associated with alien plant eradication over the ten-year project period it was essential to examine the rate of recovery over time (i.e. establishment of indigenous vegetation). The following assumption was made:

- The expected rate of recovery over time will give rise to reductions in fire management costs of: 100 per cent in the initial year, 95 per cent, 90 per cent, 85 per cent, 70 per cent, 60 per cent, 50 per cent and 45 per cent in each successive year thereafter subsequent to alien plant eradication. Therefore, the maximum reduction in fire management costs occurs in year one, followed by small increments in costs up to the point where costs reach 55 per cent of their pre-eradication levels (i.e. a sustainable saving of 45 per cent of the base year costs).

Based on this assumption, the annual reduction in fire management costs in the study region was calculated. In the first year, provided that all alien vegetation is eradicated, these costs will decline by 100 per cent or R105 476. As indigenous vegetation establishes in cleared areas, the reduction in costs declines somewhat, as shown in Figure 2. 
Figure 2 Annual reduction in fire management costs associated witb the different stages of alien plant eradication for the ten-year project

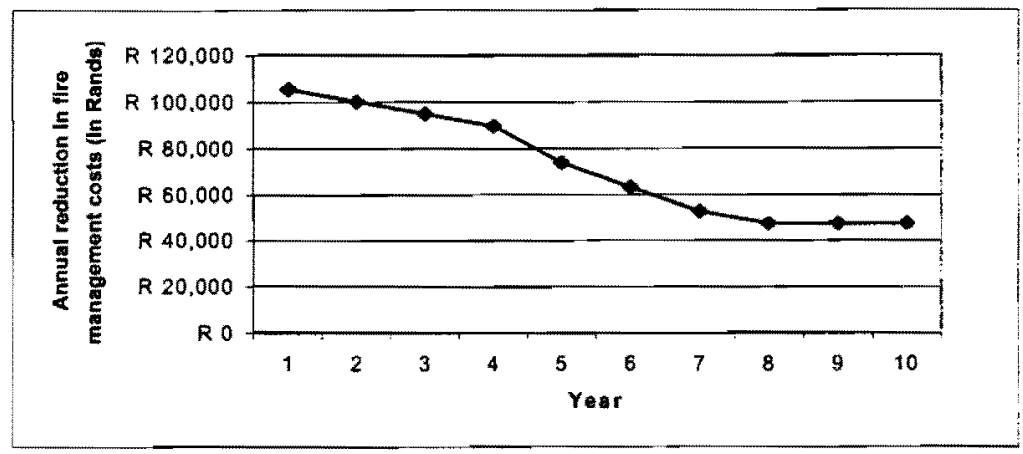

\subsubsection{Social benefits}

The social benefits flowing from alien plant eradication are those which accrue to society as a whole and include increased streamflow, increased biodiversity as well as employment benefits. It is important to incorporate these impacts into the analysis, and where possible quantify them, in order to prevent the misallocation of resources stemming from incorrect pricing information.

\section{a) Streamflow increase}

From previous studies, it is evident that streamflow reduction is positively related to vegetation biomass and age. Based on expert opinion, it was established that medium trees (which includes young Acacia and Eucalyptus species) dominate the invaded area of the study region, occupying over 70 per cent of the total invaded area (refer to Appendix I).

Using the data contained in Appendix I, streamflow reduction associated with the alien plants was calculated for riparian and non-riparian zones. The findings suggest that alien invasive vegetation in the study area reduces total streamflow by approximately 4.6 million $\mathrm{m}^{3}$ per annum. Consequently, the eradication of this vegetation is expected to increase streamflow by the same amount. It is anticipated that only a portion of this increased streamflow will be reliably captured and extracted given existing infrastructure (Wood pers comm.). Based on catchment characteristics, experts predict that a minimum of 50 per cent of the increase in streamflow (about 2.3 million $\mathrm{m}^{3}$ per annum) will be available 
for downstream use. In order to provide a more prudent appraisal, this conservative estimate was employed.

Using estimates of current water allocation in the catchment as well as the prices each sector is required to pay (refer to Table 3 ), the total monetary value associated with increased streamflow per annum was calculated. It is estimated that if all alien vegetation were removed from the study area in the first year, the monetary value of increased streamflow would amount to R422 584 (refer to Figure 4). This initial amount would be expected to decline somewhat over time, as indigenous vegetation reclaims the cleared areas.

Table 3 Current allocation of water and differential water tariffs sustained by sectors located in the Mhlatuze Catchment (van der Merwe pers comm.)

\begin{tabular}{|l|l|l|}
\hline Sectors of water use & $\begin{array}{l}\text { Current allocation of } \\
\text { available water } \mathbf{( \% )}\end{array}$ & $\begin{array}{l}\text { Current water price } \\
\text { (cents/m } \mathbf{m}^{\mathbf{3}} \text { ) }\end{array}$ \\
\hline Irrigation sector & 60 & 2.08 \\
\hline Domestic sector & 14 & 42.34 \\
\hline Industrial sector & 26 & 42.34 \\
\hline
\end{tabular}

1 Price includes infrastructure and catchment management charge

Increased streamflow arising from eradicating alien invasive vegetation accrues to those individuals situated downstream from this clearing activity, which for purposes of this study includes rural communities, private farmers as well as industries. Increased streamflow is an example of a positive externality, in that it enhances society's welfare and downstream users are able to produce at their socially optimal output level. Because of the social nature of this benefit, private individuals generally fail to take it into account when allocating resources. 
Figure 4 Annual value of the anticipated increase in streamflow over the project life span

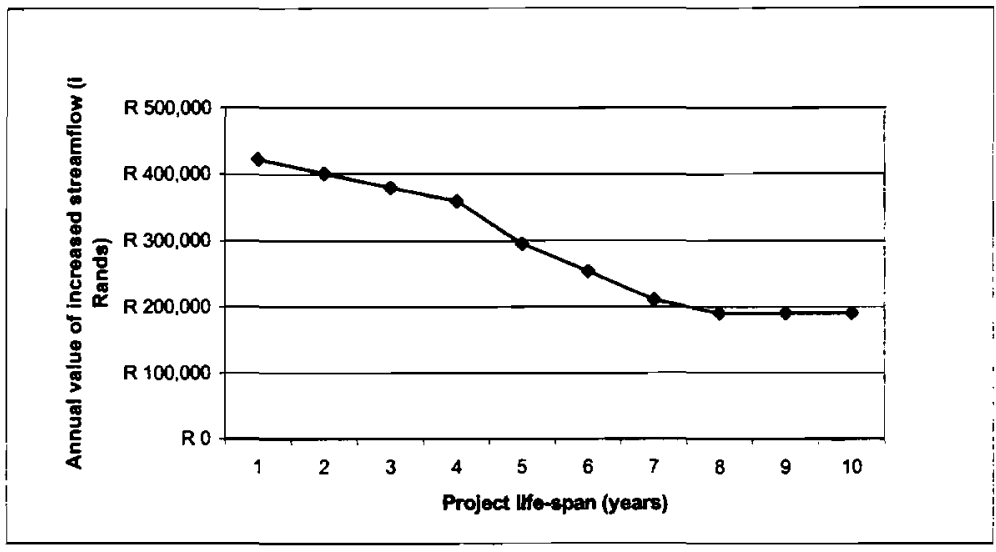

b) Increased biodiversity

Biodiversity is an important benefit flowing from the eradication of alien invasive vegetation. However, due to the complexity of critical ecosystem services and the public good aspects which biodiversity displays, it is difficult to measure and value. Techniques such as the contingent valuation method (CVM) have been developed to assign monetary values to such goods. The CVM uses surveys of expressed preferences to establish willingness to pay for (and thus, demand) the good in question. This method was employed in the present study in an effort to derive the demand for biodiversity. Eighty-five per cent of the stakeholders in the study area asserted that biodiversity was important and was a benefit associated with alien plant eradication. However, when these stakeholders were questioned directly about their willingness to pay (WTP) for an increase in biodiversity, all respondents stated zero WTP, which apparently contradicts their earlier responses.

There are several probable explanations for this atypical behaviour. First, such a non-compensatory stance can be viewed as evidence of a lexicographic preference. Individuals may express no WTP for increased biodiversity as a protest against the implication that it could be traded for other goods or money. Secondly, individuals may have experienced difficulty in comprehending the concept of biodiversity and/or the benefits that would accrue from an increase in biodiversity. Thirdly, individuals may be uncertain as to whether eradicating alien plants will give rise to increased biodiversity, since a change in the biodiversity level is often difficult to assess and/or demonstrate. (It is possible 
that the latter two problems may have persisted, despite efforts made during the interviewing process to ensure that respondents understood and accepted the concept of increased biodiversity.) Finally, biodiversity has public good characteristics and thus individuals may attempt to 'free ride', expressing no WTP for the good and concealing their true preferences in the expectation that others will sustain the cost.

Given the inherent uncertainties regarding the increase in biodiversity, rather than attempting to assign a monetary value to this benefit, it was considered more prudent to assert only that all biodiversity is valuable as a resource, and any increase therein as a result of alien plant removal would be socially desirable.

\section{c) Employment benefits}

Although the employment of individuals is essentially a cost associated with alien plant eradication, when such employment enhances the welfare of society through reduced poverty and crime levels it may also be regarded as a social benefit. It has been established that the Mhlatuze Catchment is characterised by high levels of poverty and unemployment, which have contributed to the escalation of crime and violence. Job creation arising from alien plant removal in the catchment is likely to enhance living standards and social stability in the area, and is thus of paramount importance. External social benefits of employment were not quantitatively defined in this analysis, but are highlighted here as an important additional benefit.

The magnitude of this employment benefit is contingent upon the number of labourers employed, which in turn depends on the form of alien plant control adopted. Where mechanical and chemical control methods are used, employment benefits are large - e.g. between 4 and 60 labour days are prescribed for the initial eradication of one hectare of densely invaded land (De Wit \& Crookes, 2000: 41). Bio-control methods do not compare favourably in terms of employment benefits.

Finally, it is noted that WFW Programmes could potentially provide additional benefits, such as extensive skills training. However, in the study area such benefits were not recorded.

\subsubsection{Cost-benefit analysis}

The cost and benefit flows identified above occur at different stages of alien plant eradication as well as in different years. In order to compare these flows it was essential to convert them into common units such as present values 
determined by the discounting process. The average real interest rate on longterm bonds in South Africa over the last ten years was used to define an appropriate discount rate for this project, which was five per cent. Using this discount rate, the eradication of alien vegetation in the study area would realize a Net Present Value (NPV) of R4 047703 over ten years (refer to table 4).

Table 4 Cost and benefit flows associated with alien plant eradication in the study area

\begin{tabular}{|c|c|c|c|c|c|c|}
\hline Year & $\begin{array}{c}\text { Total } \\
\text { benefits } \\
\text { (in rands) }\end{array}$ & $\begin{array}{l}\text { Final cost } \\
\text { (in rands) }\end{array}$ & $\begin{array}{l}\text { Net benefit } \\
\text { or cost (in } \\
\text { rands) }\end{array}$ & $\begin{array}{c}\text { NPV } \\
\text { Discount } \\
\text { rate 0\% }\end{array}$ & $\begin{array}{c}\text { NPV } \\
\text { Discount } \\
\text { rate 5\% }\end{array}$ & $\begin{array}{c}\text { NPV } \\
\text { Discount } \\
\text { rate } 10 \%\end{array}$ \\
\hline 0 & 12009460 & 7534000 & 4475460 & & & \\
\hline 1 & 501657 & 2862920 & -2361263 & & & \\
\hline 2 & 475,254 & $1,619,810$ & -1144556 & & & \\
\hline 3 & 448851 & 904080 & -455229 & & & \\
\hline 4 & 369642 & 715730 & -346088 & & & \\
\hline 5 & 316836 & 602720 & -285884 & & & \\
\hline 6 & 264030 & 602720 & -338690 & & & \\
\hline 7 & 237627 & 602720 & -365093 & & & \\
\hline 8 & 237627 & 602720 & -365093 & & & \\
\hline 9 & 237627 & 602720 & -365093 & & & \\
\hline Total & & & - & R-1 551529 & R4 047 703 & R4250973 \\
\hline
\end{tabular}

In order to test the sensitivity of the NPV result obtained to the discount rate, rates of 0 and 10 per cent (i.e. one standard deviation on either side of the discount rate selected) were also applied. From table 4 it is apparent that the NPV is very sensitive to the choice of discount rate. When the discount rate is 0 per cent, which means that future cost and benefit flows are not actually discounted, the NPV amounts to -R1 551529 over ten years. Under these circumstances alien plant eradication would be undesirable and rejected. However, a 5 per cent increment in the discount rate from 0 to 5 per cent, is accompanied by a R5 599232 increase in the NPV. In contrast, when the discount rate is increased from 5 to 10 per cent, NPV increases by only R203 270, to R4 250973 . The cause of these changes can be investigated by examining the cost and benefit flows associated with alien plant eradication over the ten-year period.

Although the total costs associated with the eradication of alien plants decrease with time, these are still substantial over the ten-year lifespan of the project when compared with the benefits. For all years except the current year (in which the eradication effort is assumed to be initiated), the costs of eradication outweigh the benefits. In other words, sizeable net costs (i.e. negative net 
benefits) are recorded for years 1 to 9 . The higher the discount rate employed, the lower the importance of more distant cost and benefit flows today. Thus, large net costs that stretch into the future will be substantially reduced when a high discount rate is employed, making the alien plant eradication process more desirable.

On the other hand, the largest of the quantified benefits of eradication are realised in the base year, and are not subject to discounting (because the immediate benefits from timber sales, the initial streamflow increase and reduced fire management costs are experienced as soon as clearing is undertaken). The use of a higher discount rate therefore does not affect the benefits to the same extent as the costs associated with alien plant clearing. This explains the high NPV obtained when a positive discount rate is used.

A sensitivity analysis was also performed on those variables with low confidence estimates to ascertain the effects of these on the NPV outcome. Estimates of confidence levels were based on the researcher's and expert opinion. Those assumptions with the lowest confidence estimates include increased water availability, and the water prices different sectors will be required to pay in the future. An increase in the available streamflow from 2.3 million $\mathrm{m}^{3}$ to 3.7 million $\mathrm{m}^{3}$ per year was investigated. Furthermore, an increase in the water tariff charged to the irrigation sector was postulated. The effects of both of these on the NPV outcome were found to be largely insignificant, and it can be concluded that the final NPV is relatively insensitive to changes in these variables.

Examination of the findings presented above indicates that the NPV outcome is dominated by the revenue obtained from harvesting alien vegetation, and the eradication costs. It is surmised that the final outcome will be sensitive to substantial changes in these components. All other impacts play a relatively minor role.

In summary, the CBA indicates that removing alien plants in the study area is economically viable as well as socially desirable when a discount rate of five per cent is employed. Further enhancing the argument in favour of extirpation, is recognition that the CBA undertaken for purposes of this study only examined some of the benefits associated with this project, and hence represents a minimum estimate of the benefits. 


\subsubsection{Distribution of costs and benefits}

Cost-benefit analysis per se is only concerned with the economic efficiency of a project and hence, assumes that everyone has the same marginal utility of income. Essentially this means that gains and losses, to whomsoever they accrue, are given an equal ranking in the evaluation process. This provides the rationale for selecting projects whose benefits outweigh the costs, even if those individuals who gain from a project are not the same as those who pay for it (Perkins, 1994: 55). This may result in accepting projects that are inequitable. Since policy decisions concerning alien plant eradication are the preserve of the politician, it is necessary to examine the distribution of costs and benefits, because a project which is efficient may nevertheless be undesirable if this distribution is highly skewed.

The costs and benefits associated with eradication in the study area are not proportionally distributed. In the absence of the WFW Programme and/or biological control, those individuals engaged in alien plant eradication sustain the full costs associated with this process. Although these individuals do obtain some financial gain from the commercial alien vegetation harvested and the curtailment of fire management costs, many of the benefits affiliated to eradication accrue to society in general. For example, downstream individuals can obtain monetary gain from utilising the increased water availability to augment production and furthermore, can enjoy positive effects such as increased biodiversity accruing from alien plant eradication. Consequently, there is a definite conflict of interests which prevails, as those individuals engaged in alien plant eradication must sustain the total costs associated with clearing, whilst all groups of society can essentially benefit from this clearing.

Profit-maximising individuals typically make decisions based on market prices and only consider the private costs and benefits related to a particular project when allocating resources. Consequently, such individuals are likely to engage in alien plant eradication for the initial year only, because private benefits exceed the private costs incurred in that year only (refer to Table 4). Thereafter this outcome is reversed and private costs outweigh private benefits for all subsequent years. This leads to the prediction that individuals will discontinue alien plant eradication until such time as there is a monetary incentive to continue. Such a prediction is substantiated by sporadic alien plant eradication patterns recorded at a national scale. Sporadic clearing is inefficient in the long run, since alien vegetation is never under 'proper' control and hence alien plant density is never reduced. Thus, so long as individuals do not embark on regular clearing of alien plants, they will repeatedly have to face the initial, high costs associated with clearing alien plants. In order to encourage individuals to clear 
invasive alien plants from their properties, government policy intervention is required.

\section{CONCLUSIONS AND RECOMMENDATIONS}

The issue is not whether to undertake control operations to remove alien invasive plants, but rather how to plan and execute sustainable control operations to ensure that the resources allocated to this activity are used as effectively as possible. Greater policy emphasis on and funds for curtailing widespread invasion by alien plants in South Africa are required in order to correct for the inefficiency associated with sporadic clearing.

\subsection{Removal of externalities}

The lack of alien plant eradication is an example of a negative externality which imposes costs on downstream users and is a result of the marginal private costs (MPC) consistently falling short of the marginal social costs (MSC) borne by society. In order to ensure the efficient allocation of resources it is necessary to close the gap between MPC and MSC. There are two appropriate strategies which may be adopted by government to internalise these costs namely, the introduction of a tax or a subsidy. Before these two measures are discussed it is essential to consider the socially optimal level of alien invasive plants.

\subsubsection{Definition of the optimal alien plant level}

Eradication of alien plants is economically worthwhile as long as the costs of clearing are outweighed by the (total) benefits. Thus, although this study has posited the complete eradication of alien plants in the study area, as a general point it should be noted that the optimal level of infestation in any given area is not necessarily zero. Rather, the socially optimal level of alien invasive plants is site-specific as well as species dependent, since site and species characteristics will impact on both costs and benefits of clearing. Policy-makers would need to take this into consideration in trying to define an appropriate level of a tax or subsidy to correct for the prevailing distortion in output levels.

\subsubsection{Levying of a tax}

Government can either levy a tax on individuals who are currently not engaged in alien plant clearing or alternatively, on those individuals engaged in sporadic clearing. It is important to ensure that the tax imposed for non-eradication exceeds the MPC of clearing, since only in this event will such a charge be effective in inducing individuals to remove alien plants in the long-term. 
Furthermore, the tax levied must be site-specific and charged per dense hectare of invaded alien plants.

\subsubsection{Introduction of a subsidy}

Government can subsidise those individuals that have been engaged in alien plant clearing on their properties. Subsidisation of those individuals currently engaged in clearing can be in the form of either monetary incentives or subsidising of certain costs (besides labour) incurred in clearing (e.g. herbicides). The subsidy, like the tax, should be site-specific and paid per dense hectare of invaded alien plants cleared. Subsidisation of costs or monetary measures require on-going monitoring by government officials to ensure that the resources provided are being used for the appropriate purposes.

\subsection{Supplementary measures}

\subsubsection{Fire insurance premiums}

The fire insurance premium is one measure which could be used to encourage private individuals and companies to engage in regular alien invasive plant clearing. Where individuals have removed or are in the process of removing alien plants from their land, their fire insurance premiums should be reduced because the spread of fire is much easier to control. Similarly, fire insurance premiums should be augmented where individuals have not attempted to eradicate alien invasive plants from their properties. The change in fire insurance premiums proposed will act as an incentive for individuals to engage in alien invasive plant clearing.

\subsubsection{Formulation of a weed management plan}

All those individuals owning large areas of natural land which are prone to alien plant invasion should be encouraged by government to formulate a weed management plan. This plan would entail the establishment of benchmarks which can be used to measure trends and progress towards achieving some reduced level of alien plant infestation. Such a plan is an important means of communicating information about progress towards goals set. The formulation of this plan might be encouraged by only offering subsidies to those individuals who have formulated weed management plans.

\subsubsection{Improvements of alien plant clearing programmes}

Programmes such as the WFW Programme are to be encouraged due to their potential for creating employment and thus alleviating crime and poverty, which 
is an extremely important aspect in a cash-strapped country facing massive unemployment. Based on criticisms raised by stakeholders in the study area, the following improvements to the current programme are proposed:

- To prevent animosity between stakeholders in the Mhlatuze River Catchment, it is recommended that the WFW Programme be confined to state land in the future.

- Stricter control of the current WFW Programme is required to reduce the number of conflicts between farm and WFW employees.

- Employment created by the WFW Programme per se is not a sustainable solution to the unemployment situation and it is therefore essential that WFW employees are taught skills which they can apply in other activities subsequent to the termination of the WFW Programme.

\subsection{Further research required}

\subsubsection{Impact of alien vegetation on water}

More research into the impact of alien invasive vegetation on the total available water is required. This will assist in ascertaining the actual volume of water which could in future be reliably captured and extracted for direct use, subsequent to clearing alien invasive plants. In addition, it is necessary to compare the costs of alien plant eradication to alternative schemes (e.g. dam construction) which will augment water resources in the Mhlatuze Catchment. This is important to ascertain and will indicate which are the most cost-effective in the long-term.

\subsubsection{Formulation of bio-control agents}

Continued research into the formulation of bio-control agents is required. This is important, especially since their development is likely to substantially reduce the future costs that individuals will have to sustain to effectively control alien infestations.

\subsection{Concluding remarks}

The major conclusion of this research is that there are many reasons why the eradication of alien plants is economically and socially desirable, both in terms of the efficiency and equity criteria that are generally accepted desiderata in progressive societies. The cost-benefit data for the Mhlatuze Catchment certainly suggest that alien plant eradication should be promoted in this area. It should, however, be noted that the costs and benefits presented in this study are site-specific and dependent on the type and density of alien vegetation, and that caution should be exercised in extending these conclusions to other areas. 
Furthermore, the strategic planning of alien plant clearing initiatives is critically important, given the cost of such an exercise, and thus should also be promoted by government. It follows, therefore that policy-makers should identify policies or management options that are efficient and flexible, and hence can be applied to different areas where different characteristics pertain. 


\section{APPENDIX I}

\section{AVERAGE AREAS AND AGE CLASS OF THE ALIEN VEGETATION LOCATED WITHIN AND OUTSIDE RIPARIAN ZONES IN THE STUDY AREA}

The total dense area of invasive alien vegetation (i.e. $3767 \mathrm{ha}$ ) was divided into riparian zones (i.e. 80 per cent or 3014 ha) and other zones (i.e. 20 per cent or $753 \mathrm{ha})$.

Table 1 Area and average age class of alien vegetation in riparian zones

\begin{tabular}{|l|c|c|c|c|}
\hline & W12A & W12B & W12C & $\begin{array}{c}\text { Average (W12 } \\
\text { A, B \& C) }\end{array}$ \\
\hline $\begin{array}{l}\text { Area under class 1 (tall alien } \\
\text { shrubs) }\end{array}$ & $11 \%$ & $39 \%$ & $34 \%$ & $28 \%$ \\
\hline $\begin{array}{l}\text { Area under class 2 (medium } \\
\text { trees) }\end{array}$ & $89 \%$ & $56 \%$ & $66 \%$ & $70 \%$ \\
\hline $\begin{array}{l}\text { Area under class 3 (tall alien } \\
\text { trees) }\end{array}$ & & $5 \%$ & & $2 \%$ \\
\hline $\begin{array}{l}\text { Average age class 1 (tall alien } \\
\text { shrubs) }\end{array}$ & 2 years & 2 years & 2 years & 2 years \\
\hline $\begin{array}{l}\text { Average age class 2 (medium } \\
\text { trees) }\end{array}$ & 5 years & 5 years & 5 years & 5 years \\
$\begin{array}{l}\text { Average age class 3 (tall alien } \\
\text { trees) }\end{array}$ & & 15 years & & 15 years \\
\hline
\end{tabular}

Table 2 Area and average age class of alien vegetation outside riparian zones

\begin{tabular}{|l|c|c|c|c|}
\hline & W12A & W12B & W12C & $\begin{array}{c}\text { Average (W12 } \\
\text { A, B \& C) }\end{array}$ \\
\hline $\begin{array}{l}\text { Area under class 1 (tall alien } \\
\text { shrubs) }\end{array}$ & $3 \%$ & $24 \%$ & $20 \%$ & $15 \%$ \\
\hline $\begin{array}{l}\text { Area under class 2 (medium } \\
\text { trees) }\end{array}$ & $97 \%$ & $69 \%$ & $80 \%$ & $82 \%$ \\
\hline $\begin{array}{l}\text { Area under class 3 (tall alien } \\
\text { trees) }\end{array}$ & & $7 \%$ & & $3 \%$ \\
\hline $\begin{array}{l}\text { Average age class 1 (tall alien } \\
\text { shrubs) }\end{array}$ & 2 years & 2 years & 2 years & 2 years \\
\hline $\begin{array}{l}\text { Average age class 2 (medium } \\
\text { trees) }\end{array}$ & 6 years & 6 years & 6 years & 6 years \\
\hline $\begin{array}{l}\text { Average age class 3 (tall alien } \\
\text { trees) }\end{array}$ & & 15 years & & 15 years \\
\hline
\end{tabular}




\section{REFERENCES:}

1 DE WIT, M.P. \& CROOKES, D.J. (2000) "The Costs and Benefits of Black Wattle in South Africa", Prepared for International Development Research Centre (IDRC) and Department of Water Affairs and Forestry (DWAF), Working for Water Programme. CSIR Report ENV-P-C2000023, August.

2 DWAF (2000) The Environmental Impacts of Invading Alien Plants in South Africa, distributed by DWAF, Pretoria.

3 HANLEY, N. \& SPASH, C.L. (1993) Cost-Benefit Analysis and the Environment, Edward Elgar Publishing Company, U.K.

4 HOSKING, S. \& DU PREEZ, M. (1999) "A Cost-Benefit Analysis of Removing Alien Trees in the Tsitsikamma Mountain Catchment", South African Journal of Science, 95: 442-48.

5 JUST, R.E., HUETH, D.L. \& SCHMITZ, A. (1982) Applied Welfare Economics and Public Policy, Prentice-Hall Inc, USA.

6 MUNASINGHE, M. (1993) "Environmental Issues and Economic Decisions in Developing Countries", World Development, 21(11): 172948.

7 PANAYOTOU, T. (1992) "The Economics of Environmental Degradation: Problems, Causes and Responses", In Markandya, A and Richardson, J (eds.), The Earthscan Reader in Environmental Economics, Earthscan Publications, London.

8 PERKINS, F. (1994) Practical Cost-Benefit Analysis, Basic Concepts and Applications, MacMillan, Sydney.

9 PPRI (2000) Herbicide Guide for the Control of American Bramble, Bugweed, Eucalyptus and Wattle, Unpublished document.

10 VAN WILGEN, B.W., RICHARDSON, D.M., LE MAITRE, D.C., MARAIS, C. \& MAGADLELA, D. (forthcoming): The Economic Consequences of Alien Plant Invasions: Examples of impacts and approaches to sustainable management in South Africa.

11 VERSVELD, D.B., STEYL, I. \& NELSON, P.J. (2000) Strategic Environmental Assessment for Water Use, Mhlatuze Catchment, KZN, Department of Water Affairs and Forestry, Pretoria.

Personal Communications:

GOODALL, J. (14/11/2000), Project Manager, Plant Protection Research Institute.

WOOD, J. (1 1/09/2001), Private Consultant, Pietermaritzburg. 